\title{
O USO DA TECNOLOGIA X3D PARA O DESENVOLVIMENTO DE JOGOS EDUCACIONAIS
}

\author{
Tiago Hopf - Ulbra Santa Maria - tiagohopf@ gmail.com \\ Gilse A.Morgental Falkembach - Ulbra Santa Maria - gilsemf@terra.com.br \\ Fabrício Vieiro Araújo - UFSM - rufos@ terra.com.br
}

\section{Resumo}

O ensino da Matemática vem se tornando uma atividade cada vez menos produtiva, sendo poucos os alunos que conseguem apropriar-se verdadeiramente deste saber. As dificuldades começam ainda nas séries iniciais. Os altos índices de reprovação e baixo desempenho dos alunos comprovam isso. Uma das alternativas para melhorar essa constatação é o uso de jogos educacionais na forma digital que podem tornar o processo de ensino e aprendizagem mais prazeroso, interessante com desafios que proporcionam divertimento enquanto ensinam.

Considerando a importância de jogos para o processo de aprendizagem, este artigo tem como objetivo descrever o desenvolvimento de um jogo educativo digital, em três dimensões utilizando a realidade virtual como recurso de ligação entre o aluno e o conteúdo didático. Para que isso seja possível, o jogo será desenvolvido a partir da tecnologia X3D, que é uma tecnologia em ascensão na construção de mundos virtuais para a Internet. O jogo visa a ensinar os conhecimentos básicos de Matemática para crianças das séries iniciais do ensino fundamental se constituindo em um instrumento para a construção do conhecimento.

Palavras Chaves: Jogos Educacionais - Realidade Virtual - X3D

The use of technology X3D on development of educational games

\begin{abstract}
The teaching of mathematics is becoming an increasingly less productive activity, and few students who can adapt to needs of this truly know. The difficulties start still early in the series. The high rates of disapproval and low performance of the students prove it. One of the alternatives to improve this finding is the use of educational games in digital form that can make the process of teaching and learning more enjoyable, with interesting challenges that provide fun while teach. Considering the importance of games to the learning process, this article aims to describe the development of a digital educational game, in three dimensions using virtual reality as a resource liaison between the student and the teaching content. To make this possible, the game will be developed from X3D technology, a technology that is on the rise in the construction of virtual worlds for the Internet. The game aims to teach the basic knowledge of mathematics for children of the initial series of education is essential in forming a tool for the construction of knowledge.
\end{abstract}

Keywords: Educational Games - Virtual Reality - X3D

\section{Introdução}

$\mathrm{O}$ uso da tecnologia como agente de mudança aplicada à Educação trouxe inúmeros desafios, entre eles o uso de técnicas que possibilitam projetar, desenvolver e 
implementar material educativo digital. O uso da tecnologia X3D se constitui no estado da arte da pesquisa em Realidade Virtual voltada ao desenvolvimento de jogos em três dimensões. Os jogos educacionais, no formato digital podem ser considerados objetos de aprendizagem ou objetos educacionais que são elementos construídos de forma a serem reutilizados em diferentes contextos educacionais, são recursos didáticos que subsidiam um novo tipo de educação baseada nas tecnologias digitais.

O jogo faz parte do cotidiano das crianças. A atividade de jogar é uma alternativa de realização pessoal que possibilita a expressão de sentimentos, de emoção e propicia a aprendizagem de comportamentos adequados e adaptativos. A motivação do aprendiz acontece como consequiência da abordagem pedagógica adotada que utiliza a exploração livre e o lúdico. Os jogos educacionais digitais aumentam a possibilidade de aprendizagem além de auxiliar na construção da autoconfiança e incrementar a motivação no contexto da aprendizagem.

Considerando a importância dos jogos para o processo de aprendizagem, foi desenvolvido um jogo educativo tridimensional, multimídia que por meio de desafios impostos ao aprendiz, ensina conceitos matemáticos às crianças das séries iniciais do ensino fundamental. O jogo foi desenvolvido com o uso da ferramenta Flux Studio e foi construído com a tecnologia X3D, que está em ascensão na criação de mundos virtuais, cada vez mais presentes na rede mundial de computadores. O jogo tem como cenário um labirinto tridimensional e o objetivo é achar a saída. No decorrer dos caminhos do labirinto foram colocados obstáculos compostos por expressões matemáticas para serem resolvidas e algumas opções de resposta. O aprendiz deverá responder de forma correta para seguir em frente. Esta interação faz com que o aprendiz relembre, execute e tenha motivação para aprender Matemática.

\section{Jogos Educacionais}

Os jogos educacionais, incluindo os digitais estimulam o desenvolvimento cognitivo, auxiliando na criação de estratégias para a solução de problemas. Passada a fase inicial da brincadeira, o aluno demonstra pouco a pouco uma perspectiva bastante individual de atingir o objetivo proposto e isso implica em ganhos cognitivos que ocorrem de forma gradativa. Os jogos educacionais podem explorar diversos aspectos. Os jogos de exercício, simbólicos e de construção exploram a ludicidade. Os jogos que exigem o raciocínio prático, a discriminação e a associação de idéias proporcionam a aquisição de condutas cognitivas. Os jogos que exploram a aplicação de regras, a localização, a destreza, a rapidez, a força e a concentração auxiliam no desenvolvimento de habilidades funcionais. Os jogos que ajudam a desenvolver a confiança, a autonomia e a iniciativa propiciam a aquisição de condutas afetivas. Cconsiderando que a repetição é uma condição básica para a aprendizagem o projeto de um jogo deve prever a motivação para que o aluno retorne ao jogo várias vezes. Jogos muito fáceis ou usados de forma ineficaz são descartados rapidamente. Para atrair o aluno o jogo deve ser lúdico, ou seja, deve ensinar e divertir ao mesmo tempo incorporando a diversão para estimular a aprendizagem de conteúdos e habilidades por meio do entretenimento. Com isso mantém a atenção do aluno e desperta sua curiosidade para os conceitos a serem aprendidos.

A partir dos seis anos de idade, quando a criança começa aprender a ler e a escrever, ela começa a usar mais seu raciocínio, procurando compreender os conteúdos e materiais concretos construindo assim novos conhecimentos.

Os jogos no formato labirinto servem como estímulo à criatividade do aluno e também para o fortalecimento da descoberta e refinamento de estratégias de raciocínio, pelo fato 
de que o aprendiz deve memorizar os caminhos do labirinto. O labirinto também provoca a vontade de encontrar a saída no menor tempo possível. Além disso, serve para estimular a visão espacial e desenvolver a coordenação motora por meio da estrutura do labirinto. A contribuição deste tipo de jogos para a aprendizagem está no fato de que o aprendiz constrói mentalmente a estrutura do jogo, formando seu próprio "micromundo", construindo estratégias mentais que o levam a desencadear o raciocínio. Indiscutivelmente o uso de jogos como material didático, propicia a utilização das diversas linguagens e das diversas representações geométricas além de motivar e incentivar a criatividade dos aprendizes. É um excelente recurso didático para o ensino e um dos meios mais propícios para a construção do conhecimento. Quando esses materiais digitais passam a ser usados com o objetivo educacional, assumem o nome de "Objetos de Aprendizagem".

\section{Objetos de Aprendizagem}

Os recursos oferecidos pelas tecnologias digitais têm acelerado o desenvolvimento de materiais didáticos digitais que podem ser disponibilizados na rede. Os Objetos de Aprendizagem (Learning Objects, ou Educational Objects,) se constituem um importante elemento para auxiliar qualquer modalidade de ensino com suporte tecnológico. Diversas são as definições, entre elas tem-se:

O organismo de padronização IEEE - Instituto de Engenheiros Elétricos e Eletrônicos - responsável pela definição de diversos padrões utilizados pela indústria eletro-eletrônica, por meio de seu Comitê de Padrões de Tecnologia de Aprendizagem (2000) define objetos de aprendizagem como: " qualquer entidade, digital ou não, que pode ser utilizada, reutilizada ou referenciada durante o processo de aprendizagem que utilize tecnologia".

Segundo Wiley(2000) Objetos de Aprendizagem incluem conteúdo multimídia, conteúdos instrucionais, software instrucional e software em geral e pessoas, organizações ou eventos referenciados durante um ensino com suporte tecnológico. Esta definição é generalista e permite que qualquer material seja considerado um objeto de aprendizagem, bastando que este seja utilizado em algum processo de ensino com base tecnológica.

O conceito de Objetos de Aprendizagem tem sofrido alterações segundo o autor. Porém, a partir das definições técnicas vinculadas ao seu uso na área educacional, podese dizer que objetos de aprendizagem são materiais didáticos digitais que obedecem a uma padronização no armazenamento e devem se colocados em um repositório para a distribuição na Internet, por isso pode-se dizer que o jogo desenvolvido em X3d desse trabalho é um objeto educacional. $\mathrm{Na}$ verdade, entende-se por objetos de aprendizagem qualquer material ou recurso digital com fins educacionais distribuídos por meio da Internet e/ou intranets, podendo ser disponibilizados simultaneamente para um grande número de pessoas. Objeto de aprendizagem é uma tecnologia voltada para a Educação, que pode ser definido como "qualquer recurso digital que possa ser reutilizado e ajude na aprendizagem", podendo ser implementado com qualquer tecnologia, inclusive em Realidade Virtual.

\section{Realidade Virtual}

Realidade Virtual é a forma de interface mais natural entre o computador e o ser humano. Por isso, o número de aplicações é muito grande em diversas áreas do conhecimento. A VRML (Virtual Reality Modeling Language) é a Linguagem de 
Modelagem em Realidade Virtual, surgiu no ano de 1994 com a versão 1.0, é uma linguagem para modelar mundos virtuais em 3D. Com o aumento das necessidades, novas versões surgiram como a 2.0, trazendo novas possibilidades de desenvolvimento de animações e sensores de choques dentro dos mundos virtuais, tornando-os muito mais reais, combinando-os em cenas virtuais para proporcionar uma navegação em terceira dimensão. A VRML foi projetada como uma linguagem para a web e a interação dentro dos ambientes tridimensionais é realizada por meio da Internet. É uma linguagem de programação que permite ao usuário criar ambientes virtuais tridimensionais e interativos. Os ambientes criados são chamados de mundos e estão conectados à Internet por meio da web. A tecnologia X3D, utilizada para o desenvolvimento do jogo tratado neste artigo, surgiu a partir da linguagem VRML.

A inferface homem-máquina construída por meio de objetos tridimensionais e que interagem com o usuário é um conceito de realidade virtual que cada vez mais se propaga através da Internet. Pode-se definir Realidade Virtual também como sendo uma simulação do mundo real por meio da tecnologia. Com o surgimento da Internet, aumentou a necessidade de criar um ambiente tridimensional capaz de interagir com o usuário. A idéia principal era desenvolver um jogo que qualquer escola de qualquer lugar tenha como utilizar, através do browser da Internet. A interação no jogo é estabelecida por meio de objetos tridimensionais que exibem questões matemáticas que precisam ser resolvidas para dar continuidade. Foi feita a opção pela tecnologia X3D porque ela possibilita criar aplicações simples e leves e esse é um dos motivos de sua ascensão.

\section{Características do jogo}

O jogo foi desenvolvido com base nas seguintes características:

- Monousuário ou singleplayer: apenas um jogador participa da partida. Este jogador deve percorrer o labirinto a procura da sua saída.

- Primeira pessoa: o jogador observa o jogo do ponto de vista do próprio personagem, isto é, "de dentro do mundo virtual".

- Ambiente Tridimensional: as coordenadas usadas para representar a posição de cada objeto ou entidade no mundo virtual serão tridimensionais. Todos os objetos inseridos dentro do jogo possuem 3 coordenadas de localização. Na figura abaixo, se tem uma visão de cima do labirinto desenvolvido para o jogo.

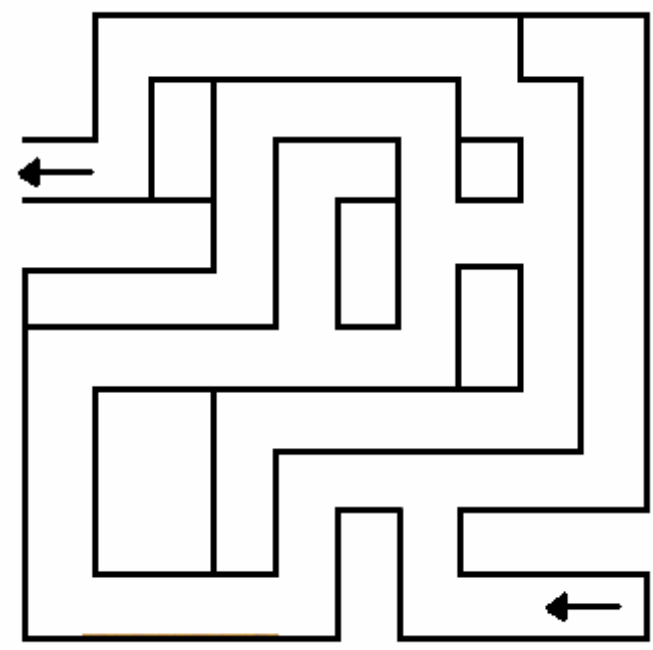


Figura 1- Estrurura do labirinto.

O jogo possui no decorrer dos seus caminhos diversas texturas e figuras infantis, utilizadas tanto nas paredes do labirinto como nos obstáculos de interação com o aprendiz, como por exemplo, animais de estimação, personagens de desenhos animados, pedras, natureza, pois segundo (Falkembach, 2005),

O cenário de um jogo deve considerar o público alvo, a faixa etária, as normas previstas na área de comunicação visual relacionadas a cores, fontes, imagens, sons e vídeos. O design da interface deve ser baseado nas teorias da percepção visual, nos conceitos de semiótica e, principalmente, nas abordagens da ergonomia.

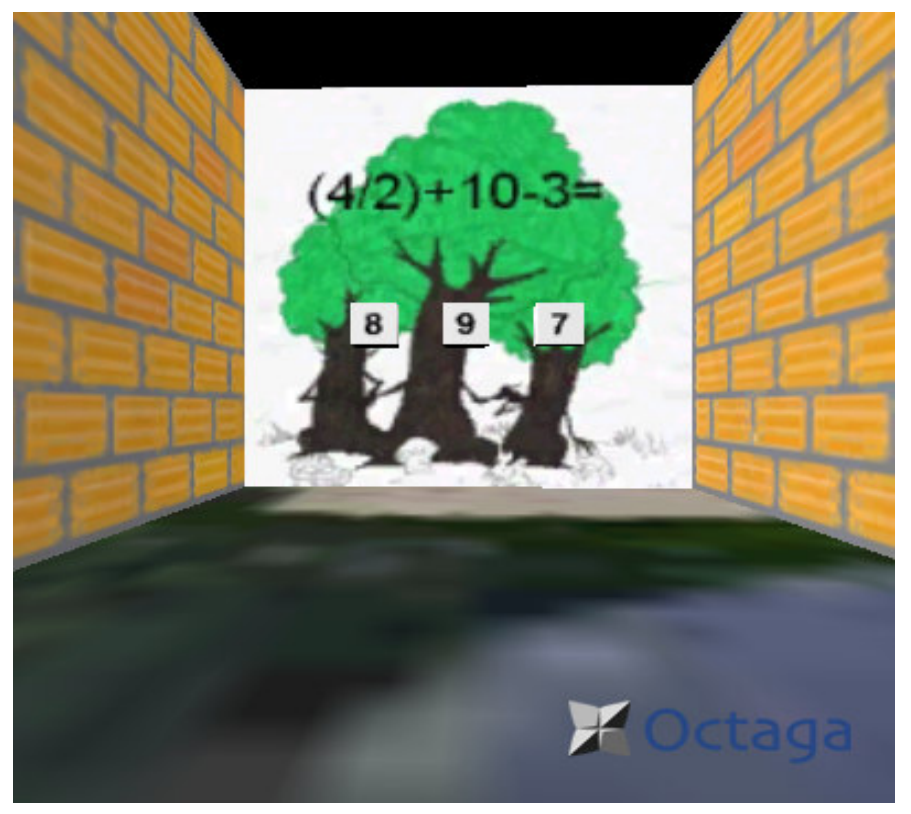

Figura 2 - Visão do jogador

Cada obstáculo encontrado tem uma chave ou código de passagem, ou seja, uma expressão matemática que precisa ser resolvida para que o jogador siga em frente. Ao selecionar a resposta correta da questão, no local de resposta, o aprendiz seguirá atrás de seu objetivo. Caso a resposta assinalada seja incorreta o jogo volta ao início, fazendo com que o aprendiz exercite as operações matemáticas até que consiga êxito nas respostas. As expressões matemáticas, para permitir ou não a passagem do jogador, estão presentes em todos os obstáculos que o labirinto possui. Elas fazem com que os aprendizes relembrem, pratiquem, ganhem velocidade de raciocínio e que os motive a jogar melhor e a aprender mais a Matemática. Abaixo tem-se uma relação de algumas expressões que são usadas como código de acesso nas portas do jogo. 


\begin{tabular}{|c|c|}
\hline Expressões Matemáticas & Respostas \\
\hline$(4 / 2)+10-3$ & 9 \\
\hline $6 * 8+1$ & 49 \\
\hline $5+[3 *(8-5)]$ & 14 \\
\hline $490 / 5$ & 95 \\
\hline $6 \times 9$ & 54 \\
\hline 1009-540 & 469 \\
\hline
\end{tabular}

Figura 3 - Exemplo de códigos de acesso

\section{Tecnologia X3D}

O desenvolvimento da comunicação em tempo real de dados 3D em todas as aplicações de rede e aplicações evoluiu desde as suas origens com o Virtual Reality Modeling Language (VRML) ao consideravelmente mais maduro e refinado X3D padrão.

O X3D é uma linguagem de descrição de cenas 3D de padrão aberto, capaz de representar e comunicar cenas tridimensionais e objetos, desenvolvida com a sintaxe XML. Essa sintaxe foi escolhida porque permite uma melhor interoperação com a web e permite incorporar novas tecnologias de forma padronizada. Para que a visualização dos arquivos X3D seja possível no browser se faz necessário a instalação de um plugin específico. A tecnologia X3D dá suporte para gráficos 3D, transformações de geometria, iluminação, materiais, texturas, mapeamento, pixels, vértices e aceleração de hardware. Permite animação com temporizadores e interpoladores de condução contínua. Permitem também interação com o mouse e entradas de teclado. A navegação no ambiente acontece por meio do uso de câmeras, com características de colisão, proximidade e visibilidade, detecção e vários tipos de iluminação. Por meio de script é possível mudar dinamicamente a cena através de linguagens de programação como o JavaScript.

\section{Desenvolvimento do jogo}

Para o desenvolvimento do jogo foi utilizada a ferramenta Flux Studio versão 2.1 da Media Machines. É uma poderosa ferrramenta para o desenvolvimento de modelagem e animação de mundos virtuais tridimensionais para web, com recurso para exportar arquivos em X3D. O jogo foi criado por meio de vários arquivos X3D separados, que são executados de acordo com o andamento do jogo. A linguagem HTML, faz a interação com os arquivos e auxilia na chamada dos mesmos. A interação dos obstáculos foi desenvolvida com o uso de um tipo de grupo da ferramenta chamado "Anchor", que funciona com um sensor dentro do jogo. Este sensor quando acionado com o mouse funciona como um gancho para o próximo arquivo $\mathrm{X} 3 \mathrm{D}$, com ajuda de scripts HTML. Algumas das telas do jogo: 


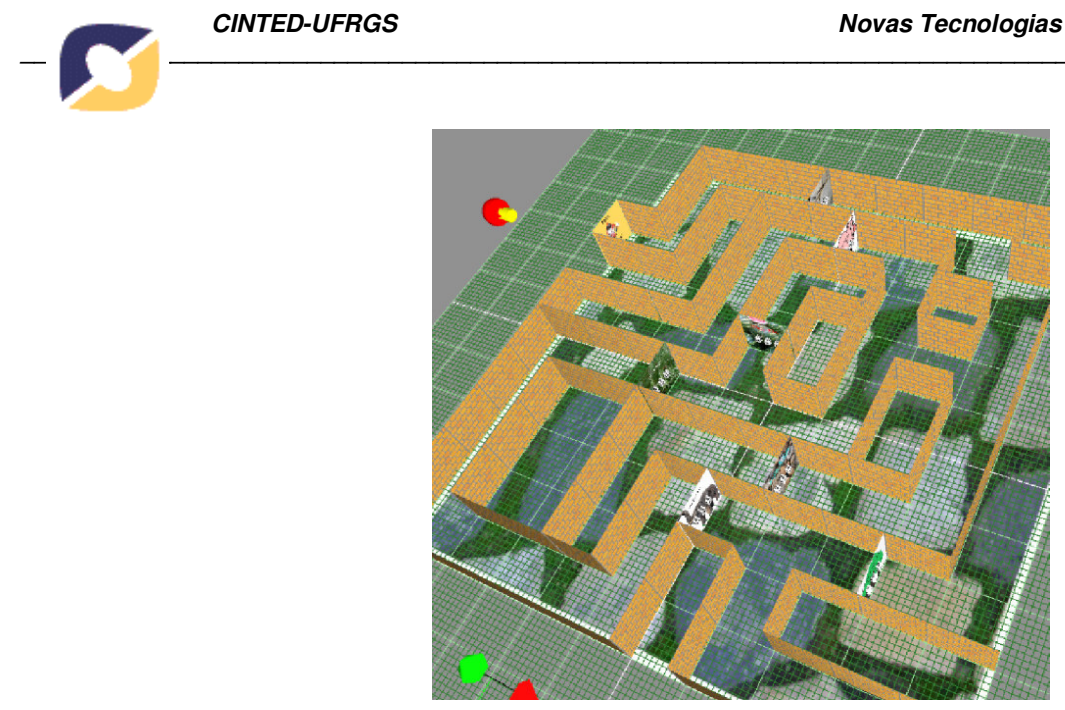

Figura 4 - Vista superior do labirinto em desenvolvimento

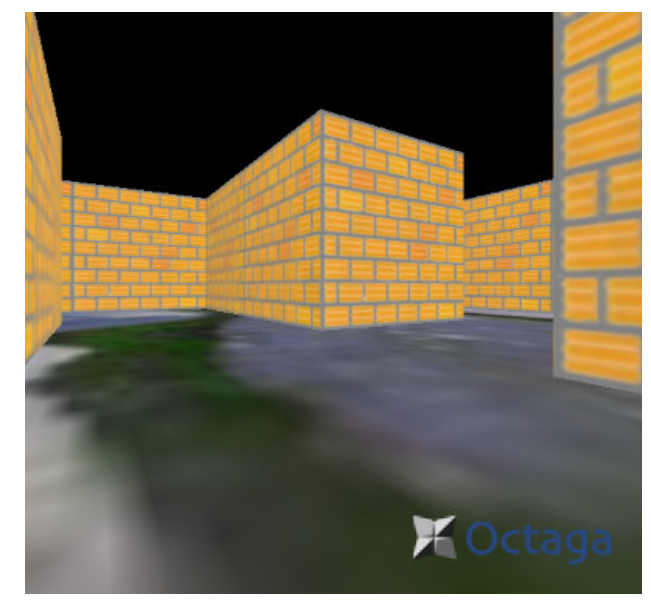

Figura 5 - Caminhos do labirinto

\section{Plugins para visualização}

Para a execução do jogo no browser é necessário o uso de um plugin para visualizar os arquivos X3D. Os plugins têm a função de ler e executar os arquivos X3D, escritos em XML no browser. Durante os testes o Browser Internet Explorer da Microsoft foi o mais adequado para o uso. Durante o desenvolvimento foram testados dois plugins, o Flux Player da Media Machines e o Octaga Player. O primeiro permite uma navegação no labirinto com as teclas direcionais do teclado e com o mouse, porém apresentou um problema de excesso de iluminação em determinadas faces do labirinto e na rotação da câmera de visão do jogador. Com o mouse a navegação é lenta inviabilizando a utilização desse plugin. Já o Octaga permita a navegação com o mouse e o teclado. A navegação com o mouse se mostrou bastante satisfatoria e a navegação com o teclado não permite a navegação do jogador na diagonal. A iluminação se mostrou bastante satisfatória para a execução do jogo.

\section{Considerações finais}

Utilizar novos recursos didáticos é fundamental, uma vez que, os alunos não estão mais satisfeitos só com quadro negro e giz. Destacar o lúdico como uma maneira de contribuir para motivar os alunos a buscar, pesquisar, construírem o conhecimento, trabalharem de 
forma cooperativa, seria uma forma de ter o educando na escola, não por obrigação, mas por vontade de aprender.

Os jogos de um modo geral desenvolvem capacidades, conhecimentos, atitudes e habilidades, entre eles, destaca-se que: favorece a mobilidade, a imaginação, a diversão, a aceitação de regras, o desenvolvimento do raciocínio lógico. Desta forma, utilizar os jogos, em especial os jogos educativos digitais, é extremamente relevante, pois, os alunos se identificam e se envolvem emocionalmente, propiciando uma aprendizagem significativa, principalmente na disciplina de Matemática, que na maioria das vezes, os alunos sentem dificuldade.

Por meio dos recursos oferecidos pelas tecnologias digitais é possível planejar, desenvolver e analisar atividades lúdicas, integrando profissionais da área técnica com os da área pedagógica para criar jogos educativos digitais. A tecnologia X3D é uma ferramenta que representa o estado da arte na construção de mundos virtuais e muito poderá contribuir para o desenvolvimento de jogos educacionais. Incorporar os jogos na Educação pode oferecer um universo complexo de significados, centrado no lúdico, subsidiando a construção do conhecimento do aluno conforme seu ritmo, de forma agradável, agregando entretenimento, informação e ludicidade e preparando-o para ser um cidadão na Sociedade do Conhecimento.

\section{Referências Bibliográficas}

CANO, Cristina Alonso. Os recursos da Informática e os contextos de ensino e aprendizagem. In: SANCHO, Juana Maria. Para uma tecnologia educacional. $2^{a}$ edição. Porto Alegre, ARTMED, 2001.

SOSTERIC, Nike, HESEMEIER, Susan. When is a Learning Object not an Object: a fisrt step towards a theory of learning objects. Internacional Review of Research in Open and Distance Learning. Outubro de 2002. Disponível em: (http://www.irrodl.org/index.php/irrodl/article/view/106/185). Acessado em 20/05/2007.

FALKEMBACH, Gilse A. Morgental. Elementos de um jogo. Centro interdisciplinar de Novas tecnologias para Educação. 2007, UFRGS.

Padrões abertos para comunicação 3D em tempo real (http://www.web3d.org/x3d/). Acessado em 15/08/2007.

Ferramenta Flux Studio 2.1 (http://www.mediamachines.com). Acessado em 18/08/2007.

FALKEMBACH, Gilse A. Morgental. Concepção e desenvolvimento de material educativo digital - VII Simpósio Internacional de Informática Educativa - SIIE05 Leiria, Portugal, 16-18 Novembro de 2005

18/08/2007.

FALKEMBACH, Gilse A. Morgental. COLLETO, Nires.RIBEIRO, Patric Desenvolvimento de habilidades cognitivas com o uso de atividades digitais - IADIS International WWW/Internet 2006 -Murcia Espanha 